\title{
Expressive Writing: A Self-Care Intervention for First Year Undergraduates
}

\author{
Monica Kennison, EdD, RN \\ Berea College \\ Connie Lamb, PhD, RN \\ Berea College \\ Judy Ponder, DNP, RN \\ Baptist Health Richmond \\ Lisa Turner, PhD, RN, PHCNS-BC \\ Berea College \\ Aryn C. Karpinski, PhD \\ Kent State University \\ Laura C. Dzurec, PhD, PMHCNS-BC, ANEF, FAAN \\ Boston College Connell School of Nursing \\ laura.dzurec@bc.edu
}

\begin{abstract}
Background: As incoming students grapple with stress and traumatic experiences at alarming rates, faculty and institutions are increasingly promoting resilience and self-care activities. Expressive writing (EW) may be an underutilized self-care practice for addressing students' stressful or traumatic experiences. Aim: This pilot study aimed to describe the effects of an expressive writing (EW) intervention on participants' mental and physical health and stress levels.

Methods: The study design was mixed methods. The convenience sample of 32 undergraduate participants were assigned, every other one, to either an EW intervention group who wrote about a stressful or traumatic experience $(n=18)$, or a neutral writing $(\mathrm{NW})$ group $(n=14)$ who wrote about trivial topics. Data regarding sample characteristics, cortisol level, quality of life, and impact of the EW intervention were collected via a demographic survey, the SF-36v2 ${ }^{\circledR}$ Health Survey (Maruish, 2011), salivary sampling and exit survey, respectively.

Results: Comparison of SF-36v2 $2^{\circledR}$ pre- to post-test demonstrated higher gains in mental health in the experimental group, relative to the control group. Fourteen (44\% of total group) reported that they would recommend EW to a friend to help with stressful or traumatic experiences.
\end{abstract}

Conclusions: EW may support first year undergraduates' self-care related to addressing past or current stressful or traumatic situations.

Submitted 12 March 2019: accepted 24 April 2019

Keywords: college populations, self-care methods/groups, stress 
Writing helps to heal (Pennebaker \& Smyth, 2016). For the past thirty years, expressive writing (EW) has been studied among both healthy and ill populations. Despite its potential utility for assisting college students to deal with stressful or traumatic experiences, it may be underutilized as a self-care technique incorporated in campus resilience and wellness programs often part of the onboarding process for incoming college students.

The prevalence of psychological disorders is greater among university students than among their community counterparts (Hussain, Guppy, Robertson, \& Temple, 2013). In a large sample of college freshmen, 81.8\% reported experiencing at least one potentially traumatic event (PTE) and 8.7\% reported experiencing four or more PTEs prior to entering college (Overstreet, Berenz, Kendler, Dick, \& Amstadter, 2017). Moreover, a history of interpersonal PTE (e.g., physical assault, sexual assault, unwanted sexual situation) was associated with trauma related distress, anxiety and depressive symptoms, and increased alcohol use (Overstreet et al., 2017).

The stress of transitioning to college, added to students' personal traumatic event exposure, may amplify student vulnerability. First year undergraduates, in particular, express concerns about the stigma, privacy, and anonymity in seeking counseling (Hussain et al., 2013). The purpose of this pilot study was to describe the utility of an EW intervention addressing stressful or traumatic experiences as a therapeutic self-care practice for first-year undergraduates.

\section{BACKGROUND}

EW has repeatedly improved health outcomes, minimized psychological and physical symptoms, and promoted overall well-being (Boals, 2012). In EW, individuals are asked to write about traumatic, stressful, or emotional life events for 15 - 20 minutes each day, on 3 - 4 consecutive days (Pennebaker \& Beall, 1986).

Over time, the "bottling-up" of feelings and related lack of disclosure about personal and traumatic experiences places individuals at risk for major and minor illnesses. EW -exposition, free writing, or journaling, for examplecan facilitate emotional disclosure and improved health outcomes that may not otherwise occur (Pennebaker \& Smyth, 2016).

A significant body of literature links EW to improved emotional and physical health outcomes for healthy college students (Alparone, Pagliaro, \& Ilaria 2015) including: fewer health center visits (Pennebaker \& Beall, 1986), less depression severity (Booker \& Dunsmore, 2017), improved self-esteem (Mum, 2014), less self-criticism (Troop, Chilcot, Hutchings, \& Varnaite, 2012), less sleep difficulty (Arigo \& Smyth, 2011) and decreased intrusive thoughts (Boals, 2012). Among Chinese undergraduates, EW improved psychological, social, and physical health (Yang, Tang, Duan, \& Zhang, 2015). Moreover, a recent meta-analysis of twenty-one independent studies of EW among youths aged ten to eighteen years (Travagin, Margola, \& Revenson, 2015) found an overall positive, yet small, mean effect size $(d=0.127)$ and significant $d$-effect sizes ranging from 0.107 to 0.246 in the domains of emotional distress, problem behavior, social adjustment, and school participation.

Given the salience of stress in the lives of many college students, the ways that students cope with stress may be a critical factor in determining who is adversely affected and may serve as a target for interventions to increase resilience and prevent mental health disorders (Coiro, Bettis, \& Compass, 2017). More than 19,000 undergraduates from 40 institutions participated in the 2018 American College Health Association (ACHA) - National College Health Assessment Survey II (ACHA-NCHA-II). Over 50\% of respondents reported experiencing three or more "traumatic 
or very difficult to handle" situations (e.g., social or intimate relationships, family problems) in the 12 months preceding their participation.

The impetus for the study reported here, as a part of a larger wellness initiative, came from an investigator review of trended data from ACHA-NCHA-II annual surveys. Those data indicated that first year undergraduates attending a rural, liberal arts college in the south fared significantly worse than did the normative group of undergraduates in reported stress levels and other physical and psychological health outcomes. Five-year average data indicated that $24 \%$ of first-year students at the involved institution came from at-risk or distressed Appalachian counties (College Fact Book, 2016-2017). To better serve students' health and wellness needs, institution administrators embarked on an extensive campus-wide wellness initiative targeting first year students at onboarding.

Study investigators sought to determine whether an EW intervention would mitigate stress and improve quality of life for incoming undergraduates during their transition to college. Quality of life was defined as the subjective assessment of health and well-being encompassing physical, mental, emotional, and social domains of life (Healthy People 2020, 2010). Stress was defined as an “individual's reaction to any change that requires an adjustment or response, which can be physical, mental, or emotional” (Townsend \& Morgan, 2018, p. 2). This study focused on first-year undergraduates' physical and mental components of quality of life as measured by the SF-36v2 ${ }^{\circledR}$ survey (Maruish, 2011) and levels of stress, as measured by salivary cortisol.

\section{RESEARCH QUESTIONS}

Three questions guided this study: (1) What are the effects of an EW intervention on the quality of life and stress level of first-year undergraduates as measured by the SF-36v2 ${ }^{\circledR}$ survey (Maruish, 2011) and salivary cortisol; (2) What stressful or traumatic experiences are described by first-year undergraduates during an EW intervention?; and (3) How does an EW intervention impact self-care of first-year undergraduates' dealing with stressful or traumatic experiences?

\section{METHODS}

\section{Design}

The mixed methods design was used to improve understanding and utility (Bazeley, 2108) of the EW. The study incorporated an experimental, two-group, pretest-posttest control group design to determine the effect of an EW intervention on student stress and quality of life. The two-groups were an EW (experimental) and NW (control) group. Qualitative data and descriptive statistics were obtained from an investigator-developed exit survey.

Following institutional review board approval two weeks prior to study initiation in fall 2016, the investigators displayed flyers advertising the study throughout campus. All first-year undergraduates over the age of 18 and attending the participating academic institution were eligible to participate in the study. The target sample comprised 419 full-time enrollees. 


\section{Participant Recruitment}

A week after the flyers were displayed, an announcement explaining the study with an invitation to participate was sent via email listserv to all first-year students. A second email announcement was sent one week after the first. Additionally, faculty members teaching first-year required courses allowed researchers to explain the study and solicit participants face-to-face prior to class. The flyer, email announcement, and face-to-face meetings listed the date and place where interested participants would meet to begin the study. A total of 39 undergraduates $(9 \%)$ responded to the recruitment efforts by arriving at the pre-determined location. The study was explained, questions were answered, and written consent was obtained.

\section{Expressive Writing Intervention}

The EW intervention consisted of four, 20-minute writing sessions conducted on each of four consecutive days. Participants were each given a notebook and pen to handwrite. Writing prompts given to participants in the EW and neutral writing (NW) control groups came from the works of Pennebaker (Pennebaker \& Beall, 1986; Pennebaker \& Smyth, 2016). Those in the EW experimental group were given a sealed envelope with the same typed prompt each day to write continuously about their deepest thoughts and feelings related to a single or multiple stressful or traumatic experience. Participants in the NW control group were given a similar sealed envelope with a typed prompt to write about a different non-emotional topic each day (e.g., a nature scene, walking directions). The writing was neither read nor kept by the researchers.

\section{Instruments}

Instruments used in the study were: demographic survey, salivary cortisol analysis, SF-36v2 ${ }^{\circledR}$ survey (Maruish, 2011), and an exit survey. Participants completed a demographic form to ascertain data on age, gender, race and academic area of interest. Participants' salivary cortisol was used to measure their stress levels and to support evaluation of the effectiveness of the EW intervention (Sanada, et al., 2016).

Quality of life (QOL) was measured with the SF-36v2 ${ }^{\circledR}$ survey (Maruish, 2011), a short-form Likert scale health survey. The SF-36v2 ${ }^{\circledR}$ survey consists of 36 items with eight scales aggregated into summary measures of physical and mental health. The Physical Component Summary (PCS) score is derived from four aggregated subscales: Physical Functioning (PF), Role-Physical (RP), Bodily Pain (BP) and General Health (GH). The Mental Component Summary (MCS) score is derived from four aggregated subscales of Vitality (VT), Social Functioning (SF), RoleEmotional (RE) and Mental Health (MH). Higher scores on the two summary measures, that is, physical and mental health, indicate better quality of life.

The SF-36v2 ${ }^{\circledR}$ survey is standardized using means and standard deviations from the 1998 and 2009 U.S. general population. The $t$-score based scores in the U.S. general population instrument have a mean of 50 and standard deviation of ten as does the SF-36v2 ${ }^{\circledR}$. Normative data from the 1998 and 2009 general U.S. adult population sample are used to compare test subjects. (QualityMetric Health Outcomes Scoring Software 5.0 Users' Guide, 2016; Maruish, 2011). The SF-36v2 ${ }^{\circledR}$ survey has been widely used as a reliable and well-validated tool to measure quality of life and, in particular, to evaluate the effects of interventions (DeBerrard \& Masters, 2014). 
The investigator-developed exit survey consisted of 11 items on a Likert scale. Survey items asked participants to describe their thoughts and feelings related to the EW intervention. The exit survey also included four open-ended questions asking participants to share the general topic of their writing and how the EW impacted them personally.

\section{Procedure}

To ensure investigator consistency in data collection and administration of the EW intervention, investigators wrote step-by-step guidelines (e.g., preprinted prompts for the EW [experimental] and NW [control] writing groups) that investigators used for data collection. On day one of the study, investigators met students in a designated private area. Enrollees signed a consent form, provided a saliva sample and completed the demographic tool and SF-36v2 ${ }^{\circledR}$ health survey (Maruish, 2011). To protect confidentiality, data were numerically coded.

Investigators collected saliva specimens using the passive drool collection approach (Granger, Johnson, Szanton, $\&$ Out, 2012). Following saliva collection procedures, investigators alternated assigning each participant to either the experimental (EW) or neutral writing (NW) control group. Investigators handed enrollees a journal, pen, and sealed plain envelope with either the EW or NW prompt. Once writing began, enrollees were timed for 20 minutes; after 20 minutes elapsed, enrollees were asked to finish their writing, notified they were free to leave with the journal, and reminded to return the following three days at the same time and place. On the following three consecutive days, the procedure was repeated. On day four, the last writing session, all enrollees were verbally reminded to return in three weeks for the posttest and second saliva sample. Those who completed the study were thanked and given a movie ticket for participation.

Because this research was conducted as part of a larger first-year health promotion initiative, researchers deemed one year an appropriate time frame for the exit survey evaluating the effectiveness of the EW intervention. Thus, at one year, participants were emailed, via Qualtrics, an exit survey with closed- and open-ended questions about the EW intervention.

\section{RESULTS}

Data analysis followed Bazeley's (2018) guidelines for how to conduct triangulation in mixed methods design, including: Creating a list of shared concepts, assessing convergence of thematic data, assessing completeness and developing a unified description. Investigators analyzed demographic data descriptively using frequency and percentage statistics (See Table 1). Of the 39 study enrollees, a sample of 32, predominantly females $(26$ or $81.3 \%)$, ranging in age from 18 to 48 (median age 19 years), completed the study. While all 18 of those in the EW group finished the study, seven ( 1 male and 6 females) assigned to the control group did not complete, a finding similar to those of other EW studies (Lancaster, Klein, \& Heifner, 2015). 
Table 1

Descriptive Statistics of Total Sample

$\mathrm{N}(\%)$

Race

$\begin{array}{lc}\text { African American/Black } & 3(9.4) \\ \text { Asian } & 2(6.3) \\ \text { Bi-/Multi-Racial } & 6(18.8) \\ \text { Caucasian/White } & 18(56.3) \\ \text { Hispanic/Latino } & 3(9.4)\end{array}$

Academic Area of Interest*

$\mathrm{BIO} / \mathrm{BUS} / \mathrm{PSYCH} / \mathrm{CFS} 12$ (37.5)

NUR/CS/MUS $6(18.8)$

Undecided/Varying 14 (43.8)

Stress Management Strategies

Exercise

Music

Television

Writing

Napping

$* \mathrm{BIO}=$ Biology, BUS $=$ Business Administration, PSYCH $=$ Psychology, CFS $=$ Child \& Family Studies, NUR $=$ Nursing, CS $=$ Computer Science, MUS $=$ Music.

The investigators used three separate Split-Plot Analyses of Variance (ANOVAs) to analyze the effects of the EW and NW intervention on the dependent variables of quality of life physical health (i.e., SF-36v2 ${ }^{\circledR}$ Physical Component Summary [PCS] scores), quality of life mental health (i.e., SF-36v2 ${ }^{\circledR}$ Mental Component Summary [MCS] scores), and salivary cortisol levels across two-time periods (i.e., pre-intervention and three-week post-intervention).

\section{Salivary Cortisol Levels}

Salivary cortisol was normalized using standard competitive ELISA test, and results were reported in ng/ml. The normal range of salivary cortisol of the total sample was $0-2 \mathrm{ng} / \mathrm{ml}$, and wide variability was evident at both pre- and posttest. Of the 32 salivary samples, $6(19 \%)$ were outliers and were eliminated from comparison testing, leaving 26 $(81 \%)$ used for group comparison. Mean cortisol level of the experimental (EW) group showed a decreasing trend from pre- to posttest, whereas the control (NW) group mean cortisol level remained relatively unchanged from preto posttest (Figure 1). 


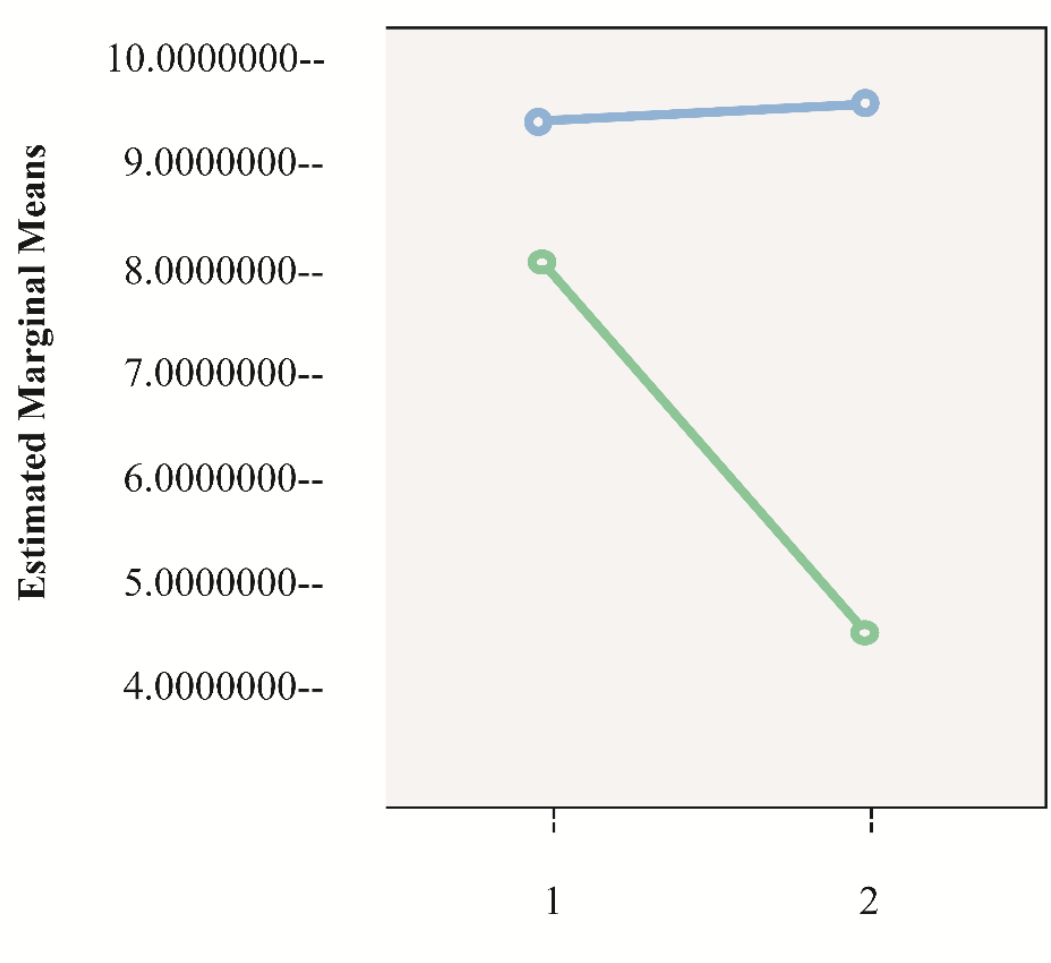

Time

\section{Experimental Group}

\section{Control Group}

Figure 1. Estimated marginal means of cortisol at pre-posttest.

\section{Physical Component Summary Score of SF-36v2 ${ }^{\circledR}$ (Maruish, 2011)}

At pre- and post-time points, the total sample, experimental, and control group scores demonstrated means above the national norm of 50.00 in physical health on the SF-36v2 ${ }^{\circledR}$ survey (Maruish, 2011). The PCS score showed little change from pre- to posttest in either group.

\section{Mental Component Summary Score of SF-36v2 ${ }^{\circledR}$ (Maruish, 2011)}

At pre- and posttest, the total sample, EW experimental, and NW control groups' scores were below the national norm on the MCS scale consistent with ACHA-NCHA-II survey results showing mental health outcomes below national norms for this population of incoming undergraduates. Table 2 shows that from pre- to posttest, the mean MCS scores of the EW experimental group increased from 35.93 to 43.35 compared to NW control group showing a trend toward improved mental health. Conversely, mean MCS scores of the NW control group remained relatively unchanged (43.03 to 41.92) suggesting the NW had no effect on control groups' mental health. Further analysis using three separate Split-Plot Analyses of Variance (ANOVAs) to determine between and in group effects of the EW intervention at pre- and posttest on the main variables of: Cortisol level, PCS and MCS did not yield statistical differences across two-time periods (i.e., pre-intervention and three-week post-intervention). 
Table 2

Descriptive Statistics of Physical and Mental QOL Stress of Groups at Pre-Posttest

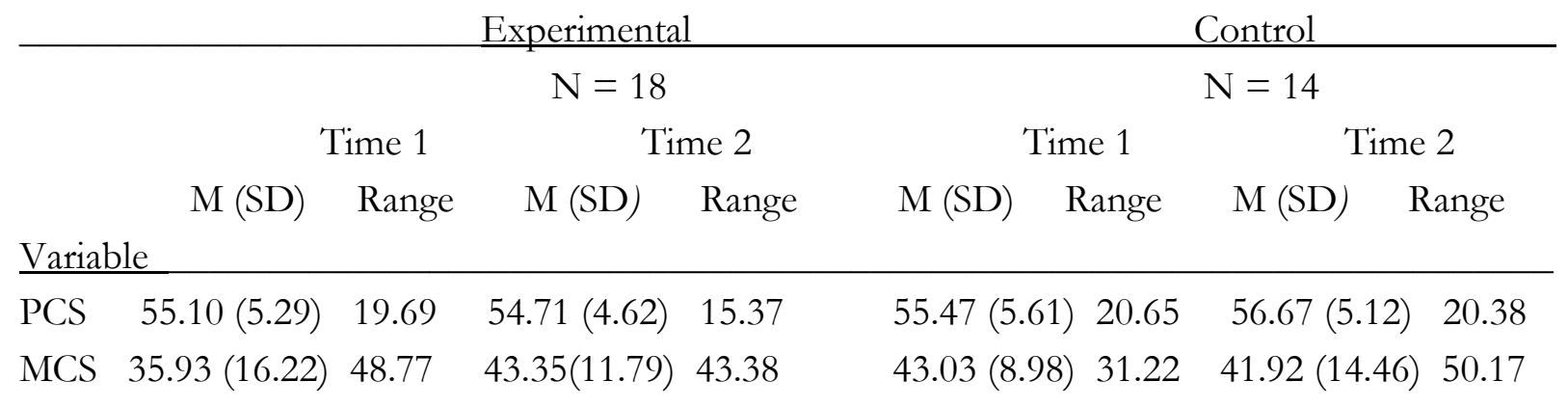

PCS = Physical Health Component Summary Score; MCS = Mental Health Component

Summary Score

\section{Exit Survey Analysis}

Fourteen of the 32 participants (44\%) provided narrative responses to the open-ended prompts on the exit survey (e.g., describe the topic of your writing, describe the impact of the EW on you personally). Descriptive statistics were used to analyze the Likert scale responses and open-ended narratives on the exit survey. In response to the item, "Writing about my deepest thoughts and feelings related to a stressful or traumatic event was helpful," $71 \%$ of respondents answered affirmatively. Eighty-six percent of respondents agreed or strongly agreed to the statement, "My time as a participant was enjoyable." Similarly, 77\% answered affirmatively to the statement, "I would tell a friend to take part in a study where one writes about his/her stressful or traumatic."

Narrative responses were analyzed using the process of repeated literal, interpretive and reflective readings (Mason, 2018) and thematic analysis (Nowell, Norris, White, \& Moules, 2017). An outside peer reviewer with expertise in qualitative analysis of narrative data verified the findings.

When asked to describe the topic of their writings, respondents described death of a family member and hometo-college transition.

"I wrote about my relationship with my late grandmother, the events leading to her death, and the aftermath of her passing. She was a tremendous presence in my life as a child, and I lost her when I was 16. I also lived with her in the two weeks leading up to her passing, which was my first time witnessing death with my own eyes. I also wrote about all the secrets that came out after she died, and how it made me feel to know them all now that I couldn't ask her about them anymore.

Transitioning from home to college was expressed differently by different respondents. One commented, "I wrote about how scared I was as an international student in America. I was quite young and have never been left home before so I felt like I did not fit into the new culture I found myself in." A second respondent differentiated between college and home life, "I mostly just talked about my life back home and [how] peaceful it was compared to my life now at ... college."

When asked about how the EW intervention impacted them, one respondent commented, 
"It was strange, writing about trauma did help me unearth these feelings to confront them, but it also put me in a fog to have them remembered inside me and replayed in my head. Although I must definitely say it's therapeutic to simply get it off your chest. Writing it is almost like telling someone about it.”

A second respondent expressed a similar comment on the therapeutic value of EW, "Writing is very helpful to me... The structure of the environment gave me a way to dive into difficult stuff and then not get stuck there, but come back out again and go on with my over-scheduled day.”

\section{DISCUSSION}

Results of this pilot study demonstrated a trend among intervention group participants toward lower cortisol levels and higher mean MCS scores from pre- to 3-week posttest when compared to the control group. However, the posttest higher mean MCS scores and lower salivary cortisol did not reach statistical significance, and that was surprising. In future studies the researchers may want to schedule an initial posttest measure of cortisol and the SF36v2 ${ }^{\circledR}$ (Maruish, 2011) closer to the intervention and consider adding exclusion criteria for medications and health problems known to alter cortisol.

The PCS score showed little change from pre- to posttest in either group. This was not surprising given all participants worked at least ten hours per week in addition to maintaining a full-time academic course load.

The findings of this mixed methods study meld into a cohesive picture that first-year undergraduates may find EW therapeutic as a self-care intervention to address stressful or traumatic experiences. An EW intervention may be a helpful complement to a multimodal wellness initiative. Further research is indicated to link EW to quality of life and stress. This is particularly germane for schools that find their incoming students fare worse than national norms of quality of life health indicators or maladaptive coping (DeBarard \& Masters, 2014).

\section{LIMITATIONS}

The small sample size at one geographic location and use of a convenience sample limit generalizability of study findings. There were no exclusion criteria regarding participants' excessive physical activity, caffeine ingestion, and current use of antibiotics, recent infection, or certain health problems that might affect salivary cortisol levels (Pritchard, Stanton, Lord, Petocz, \& Pepping, 2017). Any of those factors may have influenced results. The researchers did not screen for participants' concurrent engagement in other self-care activities (e.g., mindfulness, stress reduction) that may have impacted results.

\section{CONCLUSION}

First year undergraduates represent a vulnerable population with significant physical and mental health problems. EW proffers the privacy and simplicity that some first year undergraduates find therapeutic and would recommend to a friend to help manage stressful or traumatic experiences. Faculty and staff engaging in resilience and healthy work environment initiatives may want to further investigate EW as a complement to other self-care interventions to help students manage their current or past stressful or traumatic experiences. 


\section{REFERENCES}

American College Health Association. American College Health Association-National College Health Assessment II: Undergraduate Student Executive Summary Fall 2018. Silver Spring, MD: American College Health Association; 2018. Retrieved from https://www.acha.org/documents/ncha/NCHAII_Fall_2018_Undergraduate_Reference_Group_Executive_Summary.pdf

Alparone, F. R., Pagliaro, S., \& Rizzo, I. (2015). The words to tell their own pain: Linguistic Markers of cognitive reappraisal in mediating benefits of expressive writing. Journal of Social and Clinical Psychology, 34(6), 495-507. https://doi.org/10.1521/jscp.2015.34.6.495

Arigo, D., \& Smyth, J. M. (2011). The benefits of expressive writing on sleep difficulty and appearance concerns for college women. Psychology \& Health, 27(2), 210-226. https://doi.org/10.1080/08870446.2011.558196

Bazeley, P. (2018). Integrating analyses in mixed methods research. Los Angeles: Sage. https://doi.org/10.4135/9781526417190

Berea College. Fact Book 2016-2017. Retrieved from https:/ /www.berea.edu/ira/wpcontent/uploads/sites/27/2017/04/FactBook2016-2017.pdf

Boals, A. (2012). The use of meaning making in expressive writing: When meaning is beneficial. Journal of Social and Clinical Psychology, 31(4), 393-409. https://doi.org/10.1521/jscp.2012.31.4.393

Booker, J. A., \& Dunsmore, J. C. (2017). Expressive writing and well-being during the transition to college: Comparison of emotion-disclosing and gratitude-focused writing. Journal of Social and Clinical Psychology, 37(7), 580-606. https://doi.org/10.1521/jscp.2017.36.7.580

Coiro, M. J., Bettis, A. H., \& Compass, B. E. (2017). College students coping with interpersonal stress: Examining a control-based model of coping. Journal of American College Health, 65(3), 177-186. https://doi.org/10.1080/07448481.2016.1266641

DeBerrard, M. S., \& Masters, K. S. (2014). Psychosocial correlates of the Short-Form-36 Multidimensional Health Survey in university students. Psychology, 5, 941-949. https://doi.org/10.4236/psych.2014.58104

Granger, D. A., Johnson, S. B., Szanton, S. L., Out, D., \& Shumann, L. L. (2012). Incorporating salivary biomarkers into nursing research: An overview and review of best practices. Biological Research in Nursing, 14(4), 347-356. https://doi.org/10.1177/1099800412443892

Healthy People 2020. (2010). Foundation health measure report. Health-related quality of life and well-being. Retrieved from https://www.healthypeople.gov/2020/about/foundation-health-measures/Health-Related-Quality-of-Lifeand-Well-Being

Hussain, R., Guppy, M., Robertson, S., \& Temple, E. (2013). Physical and mental health perspectives of first year undergraduate rural university students. BMC Public Health,13, 848. https://doi.org/10.1186/1471-2458-13848

Lancaster, S. L., Klein, K. P., \& Heifner, A. (2015). The validity of self-reported growth after Expressive writing. Traumatology, 21(4), 293-298. https://doi.org/10.1037/trm0000052 
Maruish, M. E. (Ed.). (2011). User's manual for the SF-36v2 Health Survey (3rd ed.). Lincoln, RI: QualityMetric Incorporated.

Mason, J. (2018). Qualitative research. (3 ${ }^{\text {rd }}$ ed.). Los Angeles: Sage.

Mum, L. (2014). Increasing self-compassion and positive body esteem: An expressive writing intervention. Dissertation Abstracts International: Sciences and Engineering, 75(2-B)(E).

Nowell, L. S., Norris, J. M., White, D. E., \& Moules, N. J. (2017). Thematic analysis: Striving to meet the trustworthiness criteria. International Journal of Qualitative Methods, 16(1). https://doi.org/10.1177/1609406917733847

Overstreet, C., Berenz, E. C., Kendler, K. S., Dick, D. M.., \& Amstadter, A. B. (2017). Predictors and mental health outcomes of potentially traumatic event exposure. Psychiatry Research, 247, 296-304. https://doi.org/10.1016/j.psychres.2016.10.047

Pennebaker, J.W. \& Beall, S.K. (1986). Confronting a traumatic event: Toward an understanding of inhibition and disease. Journal of Abnormal Psychology, 95, 274-281. https://doi.org/10.1037/0021-843X.95.3.274

Pennebaker, J. W., \& Smyth, J. M. (2016). Opening up by writing it down: How expressive writing improves health and eases emotional pain. ( $3^{\text {rd }}$ ed.). New York: Guilford Press.

Pritchard, B. T., Stanton, W., Lord, R., Petocz, P., \& Pepping, G-J. (2017). Factors affecting measurement of salivary cortisol and secretory immunoglobulin A in field studies of athletes. Frontiers in Endocrinology, 8, 168. https://doi.org/10.3389/fendo.2017.00168

QualityMetric health outcomes scoring software 5.0 users' guide. (2016). Lincoln, R.I.: QualityMetric.

Ramler, T. R., Tennison, L. R., Lynch, J. \& Murphy, P. (2016). Mindfulness and the college transition: The efficacy of an adapted mindfulness-based stress reduction intervention in fostering adjustment among first-year students. Mindfulness, 7(1), 179-188. https://doi.org/10.1007/s12671-015-0398-3

Sanada, K., Montero-Marin, J., Diez, M.A., Salas-Valero, M., Perez-Yus, M.C., Morillo, H.,... Garcia-Camayo, J. (2016). Effects of mindfulness-based interventions on salivary cortisol in healthy adults: A Meta-analytic review. Frontiers in Physiology, 19, 471. https://doi.org/10.3389/fphys.2016.00471

Townsend, M. C., \& Morgan, K. (2018). Psychiatric mental health nursing ( $9^{\text {th }}$ ed.). Philadelphia: Davis.

Travagin, G., Margola, D., \& Revenson, T. A. (2015). How effective are expressive writing interventions for adolescents? A meta-analytic review. Clinical Psychological Review, 36, 42-55. https://doi.org/10.1016/j.cpr.2015.01.003

Troop, N. A., Chilcot, J., Hutchings, L., \& Varnaite, G. (2012). Expressive writing, self-criticism, and selfreassurance. Psychology and psychotherapy: Theory, research and practice, 86, 374386. https://doi.org/10.1111/j.2044-8341.2012.02065.x

Yang, Z., Tang, X., Duan, W., \& Zhang, Y. (2015). Expressive writing promotes self-reported physical, social and psychological health among Chinese undergraduate International Journal of Psychology, 50(2), 128-134. https://doi.org/10.1002/ijop.12081 
Author correspondence may be addressed to:

Monica Kennison, EdD, RN

Berea College

CPO 2190

Berea, KY 40404

kennisonm@berea.edu

\section{Acknowledgements}

The authors wish to acknowledge Dr. Patricia Clark of Georgia State University for suggestions on data analysis and Berea College colleagues who offered invaluable expertise: Dr. Matthew Saderholm for testing the salivary samples and Ms. Jill Gurtatowski and Dr. Maggie Robillard for help planning and implementing the EW intervention. 